\title{
Review
}

Journal of Innate

Immunity
J Innate Immun 2011;3:3-8

DOI: $\underline{10.1159 / 000322066}$
Received: September 17, 2010

Accepted after revision: October 18, 2010

Published online: November 6, 2010

\section{Coagulation in Invertebrates}

\author{
Lage Cerenius Kenneth Söderhäll \\ Department of Comparative Physiology, Uppsala University, Uppsala, Sweden
}

\begin{abstract}
Key Words
Coagulation · Comparative immunology $\cdot$ Immune

response $\cdot$ Insects $\cdot$ Invertebrates $\cdot$ Wound healing
\end{abstract}

\begin{abstract}
In most animals there is a need to quickly prevent the loss of blood or equivalent fluids through inflicted injuries. In invertebrates with an open circulatory system (and sometimes a hydroskeleton as well) these losses may otherwise soon be fatal. Also, there is a need to prevent microbes that have gained access to the body through the wound from disseminating throughout the open circulatory system. Therefore, many invertebrates possess a coagulation system to prevent such accidents from having too serious consequences. In this review we discuss recent developments in a few animals mainly arthropods - where more detailed data are available. It is likely, however, that corresponding systems are present in most phyla, but this is still unchartered territory.
\end{abstract}

Copyright $\odot 2010$ S. Karger AG, Basel

\section{Introduction}

A wound may be sealed by proteins coagulating (aggregating) in plasma in a reaction triggered by factors released by injured tissue and/or microbial or other foreign substances. In some animals, perhaps due to a very low plasma protein content, such reactions do not occur but instead blood cells adhere to each other to form a strong cellular clot. The most thoroughly characterized example is the coelomocyte clot mediated by amassin (an olfactomedin domain-containing protein) in sea urchins [1]. Strongylocentrotus purpuratus amassin is a $75-\mathrm{kD}$ protein that upon clotting forms larger disulphide-linked multimers that hook the coelomycetes up to each other via an unknown receptor [1]. Superficially, amassin aggregation resembles some plasma coagulation reactions as they occur in arthropods (see below), but no transglutaminase (TGase) seems to be involved. Recently, a cellular clotting reaction was described in detail morphologically in the sipunculan Themiste petricola [2]. This reaction may serve the same purpose as amassin-promoted cellular clotting, but no molecular data are yet available.

In many animals, though, true coagulation occurs in plasma without direct participation of the hemocytes as in the above described factors. Hemocyte-derived factors, in some cases the coagulation protein itself, are released from hemocytes during the activation of the coagulation reaction. Detailed molecular data have so far only been obtained from horseshoe crabs (Limulus polyhemus and Tachypleus tridentatus) [3] and the freshwater crayfish Pacifastacus leniusculus [4]. Recently, coagulation in insects, in particular Drosophila, has been the subject of molecular studies and the possibilities for comparing coagulation in different arthropod species are beginning to emerge [5-8]. With the exception of TGase (and,

\section{KARGER \\ Fax +4161306 1234 \\ E-Mail karger@karger.ch}

www.karger.com
(C) 2010 S. Karger AG, Basel

1662-811X/11/0031-0003\$38.00/0

Accessible online at: www.karger.com/jin
Dr. Kenneth Söderhäll

Department of Comparative Physiology, Uppsala University Norbyvägen $18 \mathrm{~A}$

SE-75236 Uppsala (Sweden)

Tel. +46 18417 2818, Fax +46 18471 6425, E-Mail Kenneth.Soderhall@ebc.uu.se 


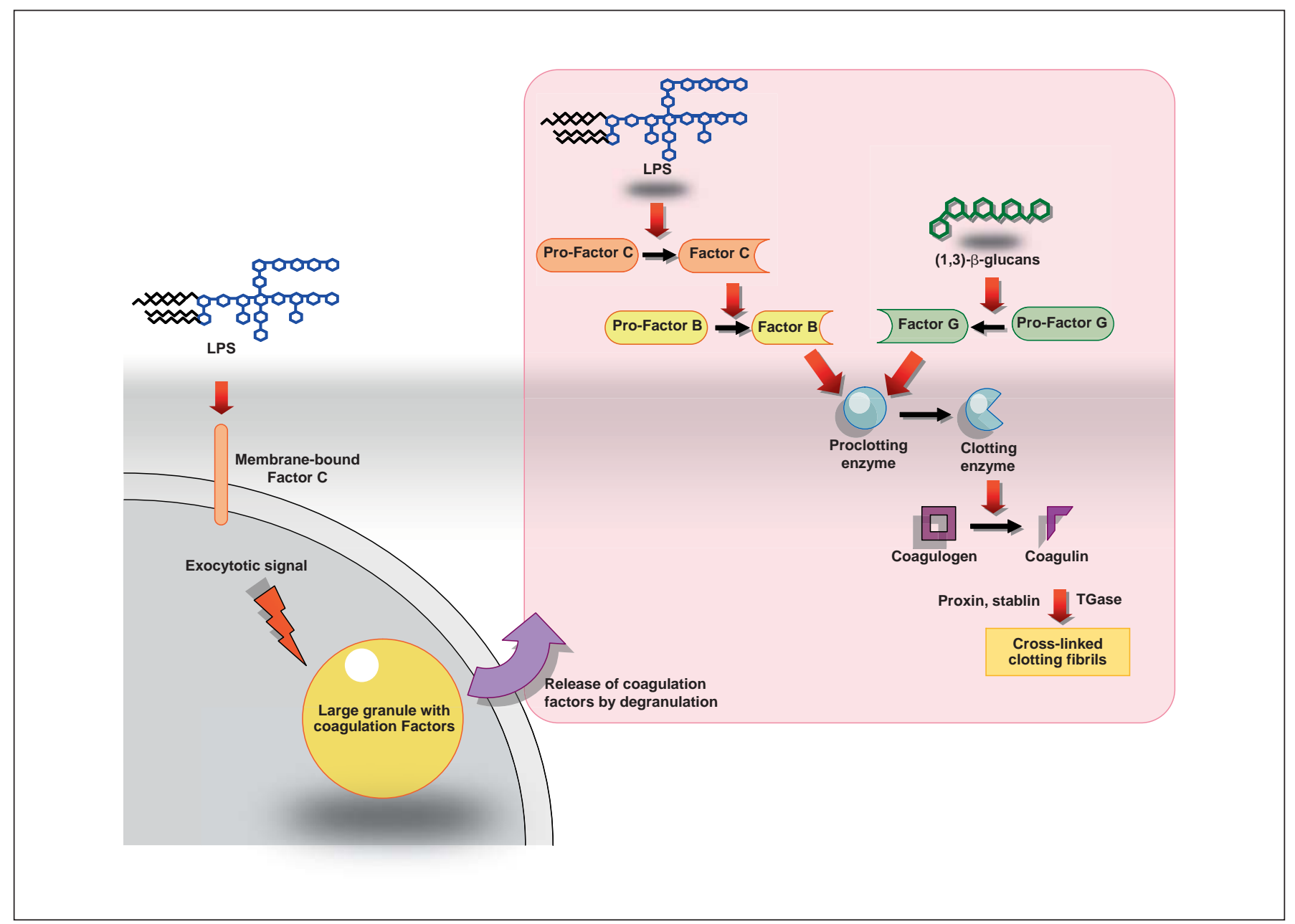

Fig. 1. Overview of the coagulation cascade in horseshoe crabs. LPS through binding to plasma membrane-bound factor $\mathrm{C}$ trigger the exocytotic release of the clotting cascade into plasma. The participating proteinases are released as enzymatically inactive proforms, but minute amounts of LPS trigger the conversion of pro-factor $\mathrm{C}$ in plasma into a proteolytically active enzyme. Factor $\mathrm{C}$ cleaves the proform of factor $\mathrm{B}$, and active factor $\mathrm{B}$ is responsible

to a limited degree, hemolectin; see below), factors participating in invertebrate coagulation lack a vertebrate counterpart and thus coagulation has apparently evolved independently in different phyla $[8,9]$.

\section{Coagulation in Horseshoe Crabs}

Hemolymph coagulation has been scientifically studied in horseshoe crabs for more than a century [3]. The discovery in the 1960s by Bang and Levin [3] that lipopolysaccharides in extremely low concentrations induce for the conversion of the proclotting enzyme into its active form, clotting enzyme. Coagulin, finally, is produced via the cleavage of coagulogen by the clotting enzyme. In a separate branch $\beta-1,3-$ glucans may induce coagulation via factor G-catalyzed cleavage of the proclotting enzyme. TGase is not required to form a gel, but the gel is stabilized by its cross-linking to proxin and stablin.

coagulation in these animals paved the way for the commercial use of the Limulus amebocyte lysate for endotoxin detection. The molecular details of how the coagulation is brought about have been deciphered by the extensive pioneering work of Iwanaga et al. [3]. In horseshoe crabs, a serine proteinase cascade (fig. 1) leads to the conversion of the soluble protein coagulogen into a gel consisting of polymers of noncovalently linked coagulin [5]. The components of the cascade are released from hemocytes in the presence of LPS. The exocytosis of clotting system components is initiated by the binding of LPS to the membrane-associated form of factor C [10]. Factor C 
is an LPS-responsive serine proteinase zymogen. It is present, as are the other components of the cascade, in the large granules of hemocytes. In addition, this protein is present in discrete areas in the cell membrane. Binding in membrane-associated factor $\mathrm{C}$ results in the exocytosis of coagulation system components including more factor C. This activation has been likened to the activation of platelets by thrombin through proteinase-activated receptors [5]. In plasma, the binding of LPS to an aminoterminal Cys-rich domain induces the autocatalytic conversion of zymogenic factor $C$ to the active proteinase. Active $\mathrm{C}$ cleaves factor $\mathrm{B}$, and factor $\mathrm{B}$ cleaves the next zymogen in the cascade, i.e. the proclotting enzyme. The proclotting enzyme, finally, transforms coagulogen into coagulin that polymerizes noncovalently. Each of the 3 participating proteinases may be regulated by a specific serpin in order to avoid and prevent the diffusion of active proteinases throughout the hemocoel. These 3 serpins possess hydrophobic consensus sequences similar to mammalian serpins, suggesting that an endocytotic clearance mechanism of reacted serpin-clotting enzymes may exist in the horseshoe crab. Although the horseshoe crab clotting cascade components are not closely related to any other characterized clotting proteins in other species, a few intriguing structural features have been noticed. Coagulogen has some structural resemblance to the Toll ligand Spätzle, and there are amino-terminal clip domains (present in several other arthropod immunerelated serine proteinases and serine proteinase homologs) in factor B and in the proclotting enzyme.

In an alternate pathway factor $G$, upon binding $\beta-1,3$ glucans, proteolytically activates the proclotting enzyme. Factor $\mathrm{G}$ is a dimeric protein with 1 larger $\alpha$-subunit with glucanase- and xylanase-like domains and a smaller $\beta$ subunit possessing the serine proteinase domain [11]. However, it is not known how glucans induce the release of the coagulation system from hemocytes. TGase is not needed for coagulin formation but is still important in the clotting process since it cross-links the clot to proxin which further stabilizes the clot [12]. This enzyme also forms cross-links between proxin and another exocytosed proteins, i.e. stablin. The latter link is likely to be crucial for the immobilization of bacteria to the clotting mesh through binding between stablin and lipoteichoic acid and LPS $[5,10]$. Hereby, the dissemination of bacteria from a wound is obstructed. In addition, stablin is probably important for the structure of the clot itself since anti-stablin antisera disturb clot formation. Importantly, activation of the coagulation system is accompanied by other defense reactions such as wound healing, activation of the primitive complement system, the release of antimicrobial factors, and the conversion of hemocyanin into phenoloxidase $[5,7]$.

\section{Coagulation and TGase in Crustaceans}

Crustacean plasma contains a large clotting lipoprotein with some structural resemblance to vitellogenin although it is clearly separated structurally from vitellogenin itself. It was first characterized in detail in P. leniusculus where the clotting protein is a homodimer whose $210-\mathrm{kDa}$ subunits are linked together by disulphide bonds [4]. Subsequently, corresponding clotting proteins have been analyzed in several crustacean species [13-16]. The carboxy-terminal contains a region similar to the $\mathrm{D}$ domain of mammalian von Willebrand factor [4]. Upon the release of TGase from hemocytes, and possibly other tissues as well, polymerization of the clotting protein is initiated (fig. 2) [4, 17]. The clotting protein forms long chains with occasional branch points. In in vitro chains containing more than 60 clotting protein molecules are assembled in less than $1 \mathrm{~min}$. Electron microscopy shows that each unit interacts at localized points instead of interacting through large surfaces. Each subunit possesses at least 1 lysine and glutamine available for cross-linking, presumably identical to local areas of interaction observed in the microscope. The participation of purified clotting protein and TGase only is enough to produce a firm gel.

In contrast to mammalians, crustaceans have 1 or 2 TGase genes only $[17,18]$. This raises the question of whether a single TGase could accomplish several functions fulfilled by a multitude of different TGases in mammals. In P. leniusculus, TGase has been demonstrated to affect hematopoiesis in addition to coagulation. The enzyme is present at very high levels in hematopoietic tissue, suggesting it is important for blood cell formation [19]. If knocked down by RNAi, cell morphology is greatly affected resulting in more spread cells [19] (fig. 3). The morphogenetic effect of TGase RNAi on these cells is strikingly similar to the effect of the prokineticin domain containing cytokine astakine [20]. In addition to inducing cell spreading, astakine treatment causes a reduction of surface-localized TGase similar to the disappearance of factor XIIIa during monocyte differentiation in mammals [19]. Furthermore, the promoter regions of the factor XIIIa gene and crayfish TGase exhibit some striking similarities with respect to GATA binding motifs and intron positions. Together, this strongly implies that crus- 
Fig. 2. Overview of the coagulation reaction in crustaceans. In contrast to coagulation in horseshoe crabs, coagulation in crustaceans is not brought about by a proteolytic cascade. Instead, a large dimeric plasma protein is covalently cross-linked into long chains by TGase. The enzyme is released from hemocytes and, in the presence of calcium ions, this enzyme carries out the polymerization reaction.

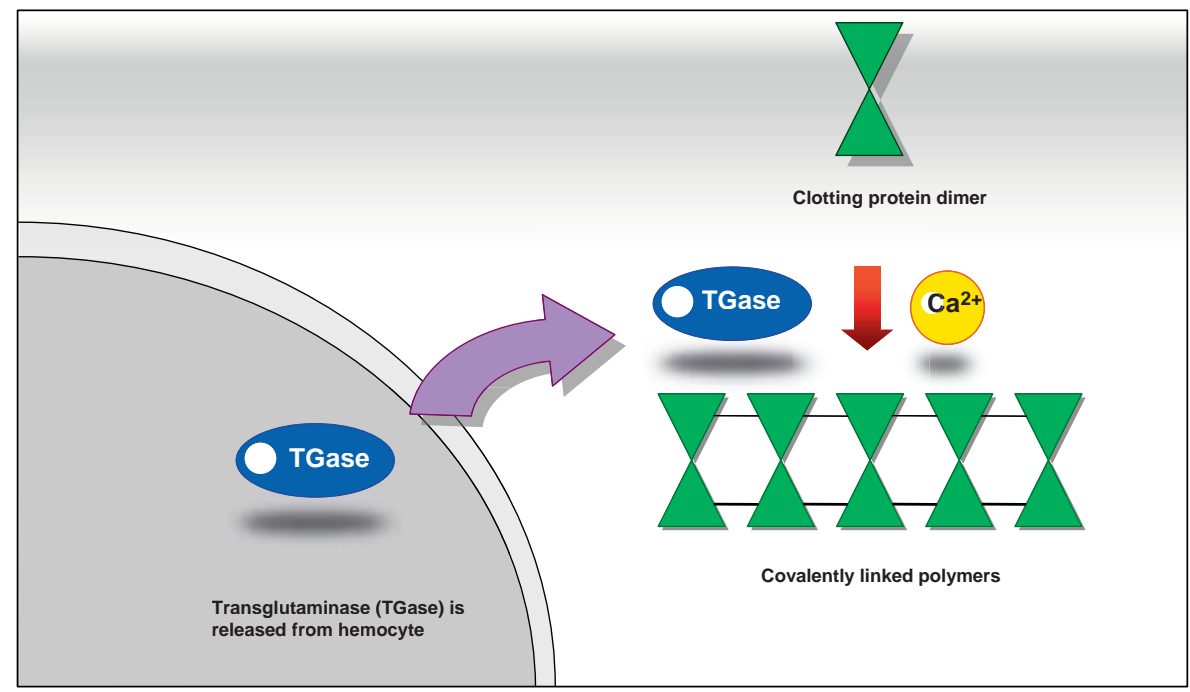

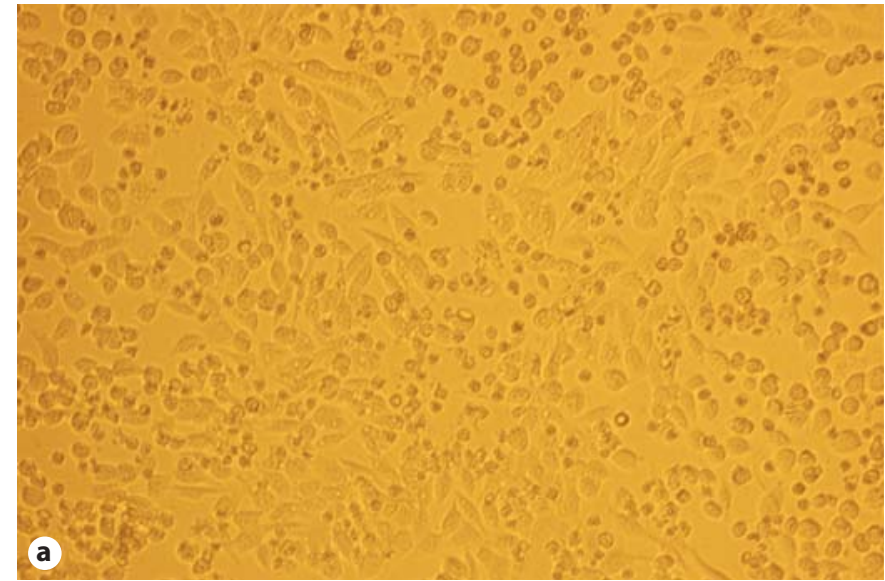

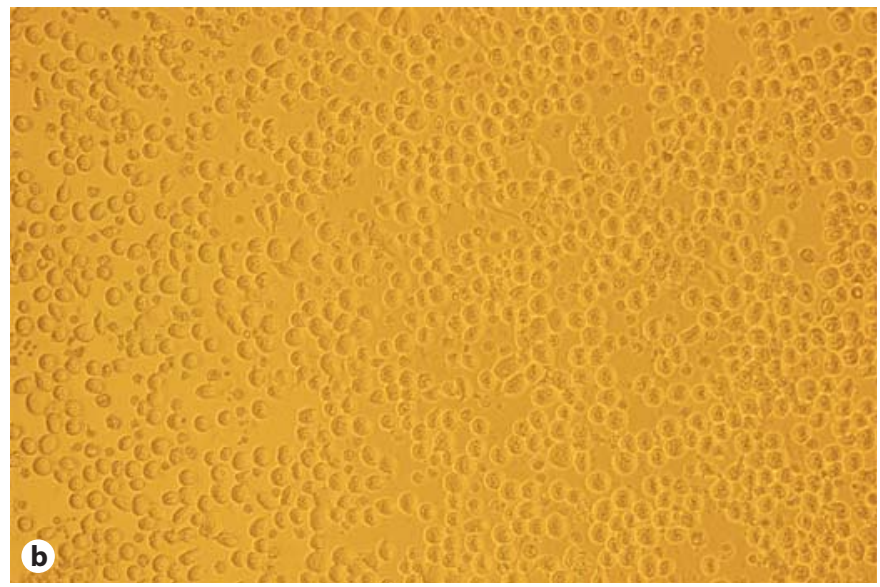

Fig. 3. Effects of RNA interference of TGase on hematopoietic cells in the freshwater crayfish Pacifastacus leniusculus. a Cells that have been treated with TGase RNAi. b Cells that are a control subjected to GFP RNAi.

tacean TGase is crucial in both hematopoiesis and coagulation. One recent finding was that astakine production and hematopoiesis are under circadian control in P. leniusculus [21]. This could indicate that clotting may differ in efficiency during the day as was demonstrated in this species for pathogen resistance in general [21].

\section{Coagulation in Insects}

From these descriptions it is obvious that the same event, i.e. the localized production of a gel in plasma, can be brought about by very different proteins in different arthropod phyla. When dealing with insects yet other proteins not related to horseshoe crab coagulogen or crustacean clotting protein come into action. A biochemical characterization of coagulation in insects as performed in some noninsect arthropods has long been hampered by their small size. In the last few years, a combined genetical and biochemical approach to this process in Drosophila larvae has resulted in the characterization of some promising candidates for coagulation proteins [6]. One likely major component of the clot is the fondue protein $[22,23]$. Its knockdown causes bleeding defects, and the presence of this protein in the clot has been demonstrated by the use of recombinant GFP-fondue [22]. 
Fondue is a major hemolymph protein and a substrate for TGase. Another coagulation candidate is Eig71Ee (gp150), which has been observed to participate in TGasedriven gel formation [22]. However, how these 3 proteins produce the clot is still not very clear. TGase is apparently necessary for producing a gel (its knockdown or inhibition prevents gel formation in vitro) although additional proteins, such as phenoloxidase, may subsequently further strengthen an already formed clot [24]. Further, 1 more protein, hemolectin, is implicated in coagulation by biochemical comparisons of pre- and postclot plasma and by the bleeding defects in a hemolectin mutant [25]. This multidomain protein contains domains found in vertebrate clotting factors such as von Willebrand factor and discoidin domains although their function in this case remains to be established. It should be noted that the clotting proteins of crayfish, shrimp, and other crustaceans also contain a von Willebrand factor domain. How these proteins and further proteins that have been associated with the clot [6] interact in Drosophila is still obscure. It should be kept in mind that due to the small size of the flies, the injuries inflicted upon them by bleeding are proportionately large and may trigger many physiological responses. This is of course difficult to avoid, but caution must be exercised when extrapolating the results of in vitro assays to conditions in vivo in such small animals.

\section{Coagulation, Wound Repair, and Immunity}

Coagulation is, for obvious reasons, closely linked to wound repair. In horseshoe crabs, the release of TGase cross-links chitin-binding proteins, i.e. caraxins, to the subcuticular epidermis [26]. Together with the coagulation clot, which binds to chitin via stablin (mentioned above), both sealing of the wound and the entrapment of intruding microorganisms may be achieved. With this in mind it is interesting to note that the Drosophila coagulation candidate fondue is localized to the cuticle as well as to the clot and that fondue knockdown gives rise to an aberrant cuticle. One possible interpretation of this result is that the fondue protein is actively involved in both coagulation and wound repair.

It seems reasonable to assume that coagulation is directly or indirectly involved in microbial killing since any wounding, outside the laboratory at least, invariably results in the exposure of hemolymph to bacteria. In Drosophila it has been reported that bacteria survive being trapped in the gel [6], but recent results show that reduced
TGase levels (achieved by RNAi) lead to immune defects and to the increased survival of some pathogens [27]. It has been suggested that this enzyme forms a complex with hexamerin and the clot matrix on the microbial surface that somehow contributes to the immune reaction [27]. In horseshoe crabs, bacteria trapped in the gel are actively killed by factors in plasma [8]. Additional circumstantial evidence for an immunological role of the coagulation reaction comes from crustaceans; clotting defects produced by RNAi of either clotting protein or TGase cause increased mortalities towards bacteria and viruses in the shrimp Penaeus monodon [16]. Whether this is best explained by an increased dissemination of the pathogens due to the defect in clotting and/or cross talk between coagulation and other arms of the immune system such as the phenoloxidase cascade ought to be studied further. In Drosophila, it was recently reported that eicosanoid inhibitors interfere with both clotting and nematode infection [28]. This may be interpreted as eicosanoids being involved in clotting in insects, which is perhaps similar to their established functions in vertebrate blood coagulation.

\section{Concluding Remarks}

Recent data strongly suggest that coagulation, wound healing, and antimicrobial activities are intimately interconnected at least in arthropods and possibly in most invertebrates. Interestingly, it was recently shown that circulating hemocytes were rapidly recruited to the sites of injury and subsequently rereleased by the healing epidermis [29]. Although it has not been demonstrated, one may speculate that these hemocytes could contribute to the clotting process. In Drosophila, it is not known what factor(s) attract the hemocytes, but a chemotactic peptide was recently identified in the moth Pseudaletia separata that possibly acts as a cytokine influencing clotting at wound sites [30]. In another insect, i.e. Galleria mellonel$l a$, experimental data indicate that released nucleic acids from damaged hemocytes/epithelial cells promote coagulation and wound repair [31]. The coagulation gel can be produced by different proteins depending on the species but invariably result in a clot trapping microorganisms and sealing wounds. However, 1 player, TGase, is apparently important for the coagulation reaction itself or for subsequent reactions taking place shortly afterwards. This possibly represents an ancient reaction aimed at cross-linking microbial components and host proteins to each other to create a foundation upon which additional 
immune reactions can work. Events such as the encapsulation or nodulation of invading microbes may share components with or directly follow a coagulation reaction.

\section{Acknowledgement}

We thank Apiruck Watthanasurorot for the assistance with preparing the drawings.

\section{References}

$\checkmark 1$ Hillier BJ, Vacquier VD: Amassin, an olfactomedin protein, mediates the massive intercellular adhesion of sea urchin coelomocytes. J Cell Biol 2003;160:597-604.

-2 Cavaliere V, Papademetrio DL, Alvarez EM, Blanco GA: Haemostatic and immune role of cellular clotting in the sipunculan Themiste petricola. Cell Tissue Res 2010;339:597-611.

$\checkmark 3$ Kawabata S, Muta T: Sadaaki Iwanaga: discovery of the lipopolysaccharide- and $\beta-1,3$ $D$-glucan-mediated proteolytic cascade and unique proteins in invertebrate immunity. J Biochem 2010;147:611-618.

4 Hall M, Wang R, Antwerpen RV, SottrupJensen L, Söderhäll K: The crayfish plasma clotting protein: a vitellogenin-related protein responsible for clot formation in crustacean blood. Proc Natl Acad Sci USA 1999;96: 1965-1970.

5 Kawabata S, Koshiba T, Shibata T: The lipopolysaccharide-activated innate immune response network of the horseshoe crab. Invertebr Surv J 2009;6:59-77.

6 Dushay MS: Insect hemolymph clotting. Cell Mol Life Sci 2009;66:2643-2650.

7 Cerenius L, Kawabata S, Lee BL, Nonaka M, Söderhäll K: Proteolytic cascades and their involvement in invertebrate immunity. Trends Biochem Sci 2010;35:578-583.

8 Theopold U, Schmidt O, Söderhäll K, Dushay MS: Coagulation in arthropods: defense, wound closure and healing. Trends Immunol 2004;25:289-294.

-9 Jiang Y, Doolittle RF: The evolution of vertebrate blood coagulation as viewed from a comparison of puffer fish and sea squirt genomes. Proc Natl Acad Sci USA 2003;100: 7527-7532.

10 Ariki S, Koori K, Osaki T, Motoyama K, Inamori K, Kawabata S: A serine protease zymogen functions as a pattern-recognition receptor for lipopolysaccharides. Proc Nat Acad Sci USA 2004;101:953-958.

11 Takaki Y, Seki N, Kawabata S, Iwanaga S, Muta T: Duplicated binding sites for $1,3-\beta$ $D$-glucan in the horseshoe crab coagulation factor G: implications for a molecular basis of the pattern recognition in innate immunity. J Biol Chem 2002;277:14281-14287.
12 Matsuda Y, Osaki T, Hashii T, Koshiba T, Kawabata S: A cysteine-rich protein from an arthropod stabilizes clotting mesh and immobilizes bacteria at injury sites. J Biol Chem 2007;282:33545-33552.

13 Yeh MS, Huang CJ, Leu JH, Lee YC, Tsai IH: Molecular cloning and characterization of a hemolymph clottable protein from tiger shrimp (Penaeus monodon). Eur J Biochem 1999;266:624-633.

14 Perazzolo LM, Lorenzini DM, Daffre S, Barracco M: Purification and partial characterization of the plasma clotting protein from the pink shrimp Farfantepenaeus paulensis. Comp Biochem Physiol B Biochem Mol Biol 2005; 142:302-307.

15 Yeh MS, Huang CJ, Cheng JH, Tsai IH: Tissue specific expression and regulation of the hemolymph clottable protein of tiger shrimp (Penaeus monodon). Fish Shellfish Immunol 2007;23:272-279.

16 Maningas MB, Kondo H, Hirono I, Saito-Taki T, Aoki T: Essential function of transglutaminase and clotting protein in shrimp immunity. Mol Immunol 2008;45:1269-1275.

17 Wang R, Liang Z, Hall M, Söderhäll K: A transglutaminase involved in the coagulation system of the freshwater crayfish Pacifastacus leniusculus: tissue localization and cDNA cloning. Fish Shellfish Immunol 2001; 11:623-637.

18 Yeh MS, Kao LR, Huang CJ, Tsai IH: Biochemical characterization and cloning of transglutaminases responsible for hemolymph clotting in Penaeus monodon. Biochim Biophys Acta 2006;1764:1167-1178.

19 Lin X, Söderhäll K, Söderhäll I: Transglutaminase activity in the hematopoietic tissue of a crustacean, Pacifastacus leniusculus: importance in hemocyte homeostasis. BMC Immunol 2008;9:58.

20 Söderhäll I, Kim YA, Jiravanichpaisal P, Lee SY, Söderhäll K: An ancient role for a prokineticin domain in invertebrate hematopoiesis. J Immunol 2005;174:6153-6160.

21 Watthanasurorot A, Söderhäll K, Jiravanichpaisal P, Söderhäll I: An ancient cytokine, astakine, mediates circadian regulation of invertebrate hematopoiesis. Cell Mol Life Sci 2010, Epub ahead of print.

-22 Lindgren M, Riazi R, Lesch C, Wilhelmsson C, Theopold U, Dushay MS: Fondue and transglutaminase in the Drosophila larval clot. J Insect Physiol 2008;54:586-592.
23 Scherfer C, Qazi MR, Takahashi K, Ueda R, Dushay MS, Theopold U, Lemaitre B: The Toll immune-regulated Drosophila protein Fondue is involved in hemolymph clotting and puparium formation. Dev Biol 2006;295: 156-163.

24 Bidla G, Lindgren M, Theopold U, Dushay MS: Hemolymph coagulation and phenoloxidase in Drosophila larvae. Dev Comp Immunol 2005;29:669-679.

25 Lesch C, Goto A, Lindgren M, Bidla G, Dushay MS, Theopold U: A role for Hemolectin in coagulation and immunity in Drosophila melanogaster. Dev Comp Immunol 2007;31: 1255-1263.

26 Matsuda Y, Koshiba T, Osaki T, et al: An arthropod cuticular chitin-binding protein endows injured sites with transglutaminasedependent mesh. J Biol Chem 2007;282: 37316-37324

-27 Wang Z, Wilhelmsson C, Hyrsl P, Loof TG, Dobes P, Klupp M, Loseva O, Mörgelin M, Iklé J, Cripps RM, Herwald H, Theopold U: Pathogen entrapment by transglutaminase a conserved innate immune mechanism. PLoS Pathog 2010;6:e1000763.

-28 Hyrsl P, Dobes P, Wang Z, Hauling T, Wilhelmsson $\mathrm{C}$, Theopold U: Clotting factors and eicosanoids protect against nematode infections. J Innate Immun 2010;3:65-70.

29 Babcock DT, Brock AR, Fish GS, Wang Y, Perrin L, Krasnow MA, Galko MJ: Circulating blood cells function as a surveillance system for damaged tissue in Drosophila larvae. Proc Natl Acad Sci USA 2008;105:1001710022.

-30 Nakatogawa S, Oda Y, Kamiya M, Kamijima T, Aizawa T, Clark KD, Demura M, Kawano K, Strand MR, Hayakawa Y: A novel peptide mediates aggregation and migration of hemocytes from an insect. Cur Biol 2009;19: 779-785.

31 Altincicek B, Stötzel S, Wygrecka M, Preissner KT, Vilcinskas A: Host-derived extracellular nucleic acids enhance innate immune responses, induce coagulation, and prolong survival upon infection in insects. J Immunol 2008;2705-2712. 